\section{NEWS INFOCUS}

- Björklund, to launch a new trial, which is funded by the European Union, involving fetal dopaminergic-neuron transplants. Known as TRANSEURO, it will monitor disease progression in 150 patients in the United Kingdom, Sweden, France and Germany. The first patient is due for transplantation next month at Addenbrooke's Hospital in Cambridge. In line with the retrospective findings, the average age of trial participants at recruitment was 55 , and their average disease duration just 4 years. None had displayed dyskinesias - uncontrolled muscle movements that can be a side effect of L-dopa treatment.

But stem-cell biology has advanced significantly since 2003, and dopaminergic neurons can now be derived from human embryonic stem cells and also from induced pluripotent stem cells - mature cells that have been rewound to an uncommitted stem-cell-like state and that can be coaxed to become a cell type of choice. These potential sources are more desirable than those derived from fetuses, because fetal cells are hard to come by and their biology varies.

Research is under way to ensure that the stem cells develop into the exact type of dopaminergic cell needed to treat Parkinson's and that they become correctly integrated into recipients' brains. But progress has been so fast that clinical trials are already on the horizon. A Japanese trial, using induced pluripotent stem cells, is planned to start in Kyoto within two years; and two trials using human embryonic stem cells are also planned, one to begin within three years in New York and the other in Europe within four to five years.

The Parkinson's Disease Global Force hopes that its joint planning will make comparing outcomes easier. Members will share their protocols for deriving and grafting cells, as well as their clinical criteria for patient selection and follow-up.

They see the TRANSEURO trial as a pathfinder. "We don't know yet which source of cell will turn out to be the best, but right now the fetal cell is the gold standard we need to match," says neurologist Claire Henchcliffe from the Weill Cornell Medical Center in New York, who is coordinating the working group's guidelines on patient assessment and trial design.

The stem-cell approaches have a long way to go before they can rival the promise of fetal cells, says Lund University stemcell biologist Malin Parmar, a member of the European clinical-trial team. That is because the cells from fetal brains are already on the way to becoming mature dopaminergic cells. "The human body knows very well how to develop each cell type from the embryo," she says. "We haven't learnt all of these secrets yet, but we have learnt some major ones." -

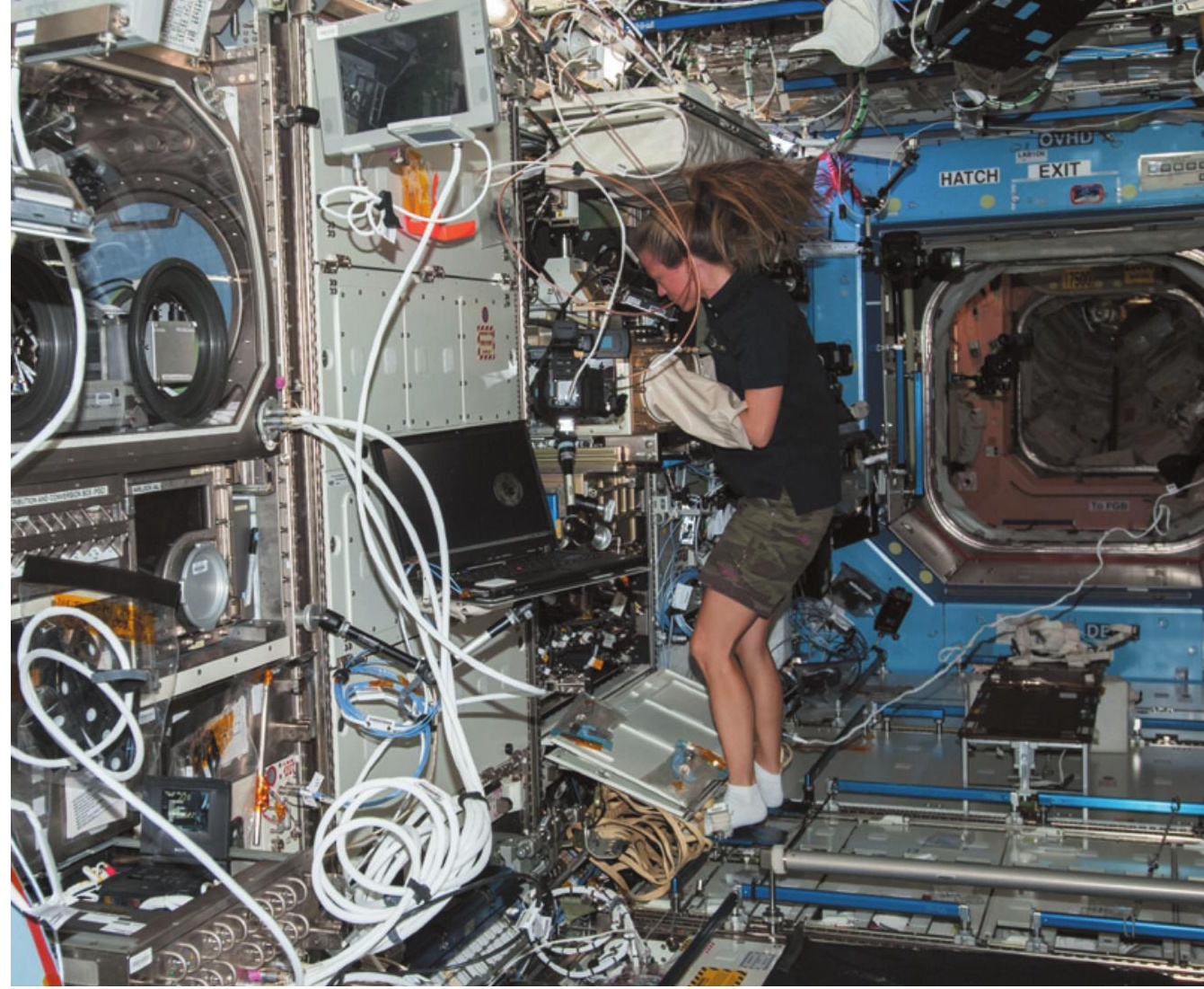

NASA astronaut Karen Nyberg works on a colloid experiment aboard the International Space Station.

\title{
SPACE
}

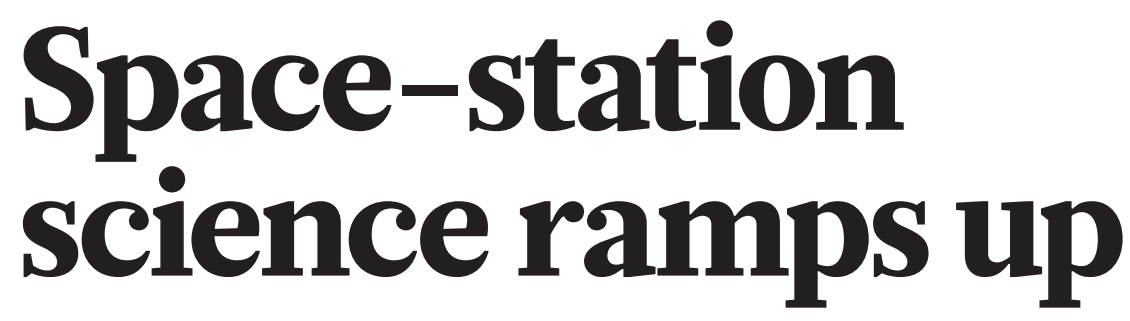

NASA pushes research agenda in face of Russian resistance.

\section{BY ALEXANDRA WITZE}

I n January, when the United States proposed extending International Space Station (ISS) operations until 2024, the world was a very different place. That was before Russian military intervention in Ukraine, before US-Russian relations foundered and before Russian deputy prime minister Dmitry Rogozin suggested that US astronauts use a trampoline to get themselves to orbit (see Nature http://doi.org/s4f; 2014).

Rogozin also suggested last month that Russia would stop participating in the spacestation programme after its scheduled end date of 2020. That statement did not set official government policy, but given Russia's key role in the orbiting outpost it cast a shadow over hopes for the four-year extension.

With the clock ticking, the race is on to conduct as much science as possible in whatever time the space station has left. At a conference next week in Chicago, Illinois, NASA scientists will try to lure researchers who have not worked with near-zero-gravity conditions before. The goal is to get them to propose anything from the usual research agenda - such as protein crystallization and human physiology experiments - to basic biomedical research and Earth-science observations that can take advantage of the highflying platform before its mission ends (see 'Research push'). "There's never been anything like it," says Julie Robinson, NASA's spacestation research chief at the Johnson Space Center in Houston, Texas. "It's like a university, all together with all the disciplines - I don't know if we'll see that again."

More than 1,600 scientists from 69 countries have contributed to experiments carried out on the space station since its first module was launched in 1998. The United States is the largest science user. But over the years, many have questioned the value of the science done in orbit. One main goal is to help humans to endure long-duration spaceflight, but early experiments often failed. For instance, NASA astronauts would spend hours a day exercising on treadmills to slow down muscle wasting and bone loss - to little avail. Force measurements revealed that they were subjecting their bodies to stresses that were not 


\section{RESEARCH PUSH}

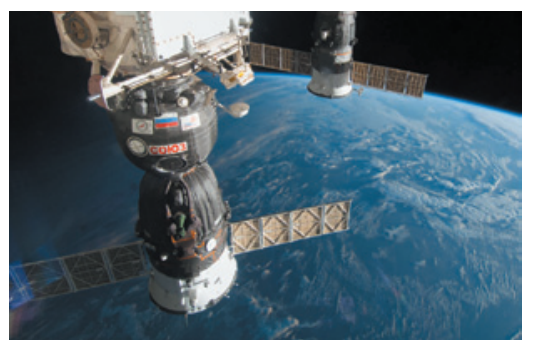

The United States has proposed extending the International Space Station's lifetime by four years, to 2024 , to conduct more scientific research.

This year, the station will see the arrival of multiple science payloads.

1 JULY Launch of Orbital Sciences cargo ship, which includes student experiments.

\section{JULY Launch of Automated} Transfer Vehicle cargo ship and experiment supplies.

\section{AUGUST Launch of SpaceX ship,} including rodent habitat and RapidScat ocean-wind monitor.

\section{SEPTEMBER Launch of SpaceX} cargo ship with cloud-aerosol laser instrument.

even close to the pull of gravity on Earth.

Another goal has been to conduct basic scientific observations to see how physical and biological processes change in a nearweightless environment. But these studies have often been limited to growing relatively unimportant proteins or running student experiments, and have often not made fundamental breakthroughs. In a sharply critical 2011 report, a US National Research Council panel argued that NASA was "poorly positioned to take full advantage of the scientific opportunities offered by the now fully equipped and staffed ISS laboratory".

Space-station research suffered further after NASA halted the space-shuttle programme in 2011, eliminating the only option for both delivering experiments to orbit and returning them to Earth.

But in late 2012, the debut of two-way cargo ships made by private company SpaceX of Hawthorne, California, again allowed samples to be returned to Earth. That development enabled experiments such as those of David Klaus, an aerospace engineer and gravitational biology researcher at the University of Colorado Boulder, who is exploring why antibiotics seem to work less well in space than on the ground. The answers might help in making the drugs perform better on Earth, he says - and running operations to 2024 would allow him more generations of experiments, with the results of each guiding the design of the next.

"Extending the station out that long helps us align a bit better with research portfolios here on the ground," says Duane Ratliff, chief operating officer at the Center for the Advancement of Science in Space, an organization in Melbourne, Florida, that manages US spacestation research for NASA.

Another strategy is to mount Earth-science experiments on the space station as a cheaper alternative to putting them on a free-flying satellite. Some time in August or later, an instrument that monitors ocean winds will be flown to the station to replace a satellite-borne one that failed in 2009. And a supply run in September is slated to deliver a laser system to measure clouds, dust and pollution in the Earth's atmosphere.

The agency is also adding what it hopes will be versatile facilities that produce data for a broad range of research. The August supply run will carry a rodent habitat the largest ever launched for long-duration spaceflight, says Robinson, with a capacity of 40 mice. And a series of experiments called geneLAB will send a range of model organisms, including fruit flies and nematodes, into space for months at a time, performing basic biomedical assays on them both in orbit and after returning them to Earth. The accumulated information will go into a database that any ground-based researcher will be able to draw on.

"People will come and do one to two experiments in space," says Robinson, "and continue to do work in their lab for another 30 years to understand that insight."

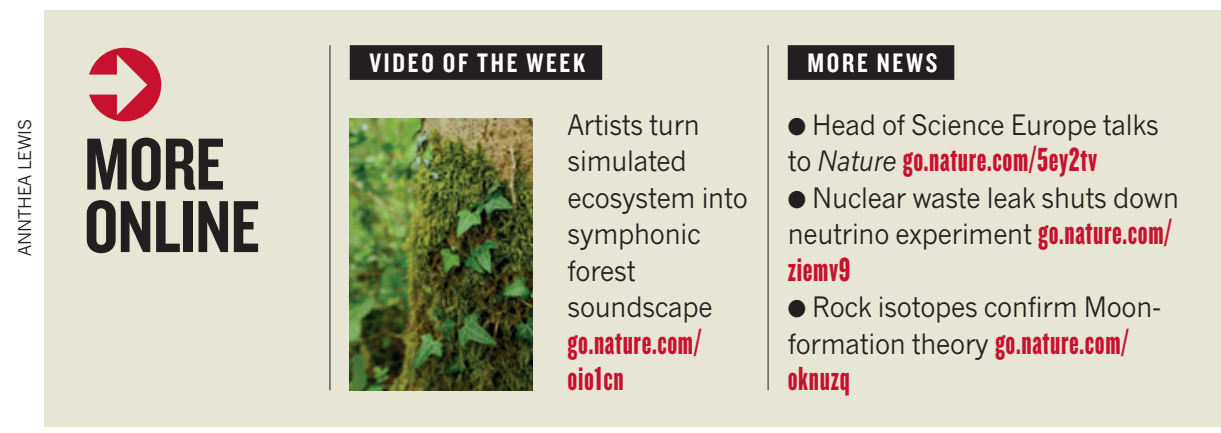

